\title{
Peroxidase Activity, Isoenzymes, and Tissue Localization in Developing Highbush Blueberry Fruit
}

\author{
T.J. Miesle', A. Proctor ${ }^{2}$, and L.M. Lagrimini ${ }^{3}$ \\ The Ohio State University, Columbus, OH 43210-1096
}

Additional index words. ripening, lignin, tissue prints, Vaccinium corymbosum

\begin{abstract}
The activity, isoenzymes, and histochemical location of peroxidase were studied in developing highbush blueberries (Vaccinium corymbosum $L$.). Total peroxidase activity increased during development when expressed on a fresh-weight basis, reaching a maximum in red berries and then declining. When peroxidase activity was expressed per berry it did not decline after the red-berry stage. Most of the enzyme was ionically bound to cell walls throughout development, with the number of isoenzymes increasing with maturity. Histochemical localization of peroxidase showed that enzyme activity spread throughout the berry during development.
\end{abstract}

Peroxidase (POD) is found in most plant tissues and has been proposed to have various functions related to fruit ripening; these include cell wall synthesis (Lamport, 1986), changes in cell wall plasticity (Goldberg et al., 1986), Signification (Catesson et al., 1986), degradation of indole-3-acetic acid (IAA) (Grambow, 1986), and anthocyanin breakdown (Grommeck and Markakis, 1964).

In view of the continuing increase in blueberry production (Eck, 1988), factors that affect the stability and quality of fresh and processed fruit will become more important. Flavor, texture, and color are particularly crucial. Predicted roles for peroxidase in anthocyanin degradation and cell wall structure may influence color and texture, respectively. In addition, POD is known to catalyze off-flavor formation by promoting lipid oxidation (Love, 1985). Blueberry lipids contain a large proportion of unsaturated fatty acids (Wang et al., 1990), which would be particularly susceptible to lipid oxidation. Peroxidase activity is also induced by mechanical stress (Lagrimini and Rothstein, 1987; Miller and Kelley, 1989), as encountered during handling and processing.

Little work has been done on blueberry POD. Frenkel (1972) reported diminishing expression of POD activity in highbush blueberries during ripening. He found that this activity did not correspond with IAA oxidase activity.

The focus of this investigation is on fruit POD activity, isoenzymes, and histochemical location in developing blueberries. Spatial and temporal changes in POD activity may give an indication as to the role of peroxidase during fruit ripening and relevance to postharvest storage and processing.

\section{Materials and Methods}

Harvest. Highbush 'Collins' blueberries were harvested at various stages of development from a commercial blueberry farm at Mount Vernon, Ohio, during the 1989 season. Care was taken to pick only healthy, undamaged fruit. Blueberries were

\footnotetext{
Received for publication 8 June 1990. Manuscript no. 203-90. Salaries and research support provided in part by state and federal funds appropriated to the Ohio Agricultural and Research Development Center, The Ohio State Univ. The cost of publishing this paper was defrayed in part by the payment of page charges. Under postal regulations, this paper therefore must be hereby marked advertisement solely to indicate this fact.

'Graduate student, Dept. of Food Science and Technology.

${ }^{2}$ Assistant Professor, Dept. of Food Science and Technology, to whom reprint requests should be addressed.

${ }^{3}$ Assistant Professor, Dept. of Horticulture.
}

separated into stages 2-8 as described by Ballinger and Kushman (1970). Stage 2: The berries are light green to whitish, enlarging rapidly but with no visible red color. Stage 3: The fruit are the same as stage 2 but with a trace of red visible at the calyx end. Stage 4: About half the surface of the berry is red (calyx end). Stage 5: Except for a small area at the stem end that is greenish-white, the berry surface is totally red. Stage 6: The entire berry surface is bluish-red except for a trace of red color near the calyx end. Stage 7: The whole berry surface is blue without a distended stem scar. Stage 8: The berry appears totally blue and more shallow from stem to calyx than stage 7, with a distended stem scar.

The blueberries to be used for POD assay and isoenzyme separation were immersed in liquid nitrogen in the field and stored at $-80 \mathrm{C}$. The fruit used for the histochemical studies were not frozen, but analysis was performed within $3 \mathrm{~h}$ of harvest.

Enzyme extraction. Fruit from stages 2-8 (5 g for each) were homogenized on ice with a Polytron apparatus (Brinkman Industries, Westbury, N. Y.) in $60 \mathrm{mM}$ sodium phosphate buffer ( $\mathrm{pH}$ 6.0) containing $1 \mathrm{mg}$ sodium bisulfite/ml to retard browning. The fruit : extraction medium ratio was $1: 3(\mathrm{w} / \mathrm{v})$. The homogenate was centrifuged at $11,000 \times \mathrm{g}$ for 10 rein, and the clear supernatant removed.

To distinguish soluble from ionically bound forms of POD, the extraction procedure was also performed with $0.2 \mathrm{M}$ calcium chloride added to the medium. Cell-wall-bound POD previously has been shown to be extracted with a concentrated salt solution (Ranadive and Haard, 1972).

POD assay. The activity of the extracts prepared with and without added $\mathrm{Ca}$ was measured, in duplicate, as described by Lagrimini and Rothstein (1987). Increase in the absorbance at $470 \mathrm{~nm}$ was measured by adding the extract to $0.28 \%$ guaiacol, 0.05 M sodium phosphate buffer ( $\mathrm{pH} 6.0$ ), and $0.3 \%$ hydrogen peroxide at $20 \mathrm{C}$.

Isoelectric focusing. We found the POD activity obtained using a $\mathrm{Ca}$-free extraction medium to be too low to detect on isoelectric focusing gels, and the $\mathrm{Ca}$ in the high-salt extract interfered with gel performance. Thus, the prepared extracts were brought to $80 \%$ ammonium sulfate saturation and centrifuged at $12,500 \times \mathrm{g}$ for $20 \mathrm{~min}$. The supernatant was decanted, and the pellet was resuspended in a small amount of water and dialyzed for $48 \mathrm{~h}$ in $0.5 \mathrm{M}$ phosphate buffer $(\mathrm{pH} 5.0)$. The

Abbreviation: POD, peroxidase. 
suspension was clarified by centrifugation at $8000 \times \mathrm{g}$ for 10 min and concentrated with an Amicon filter apparatus (Amicon Corp., Beverley, Mass.), molecular weight cut off 10,000. This material was then subjected to isoelectric focusing.

Flat-bed isoelectric focusing and in situ POD-activity staining were performed as described by Lagrimini and Rothstein (1987), with minor modifications. Protein obtained from the equivalent of $45 \mathrm{mg}$ of berry tissue was used for each growth stage. Focusing was performed on polyacrylamide gels containing ampholines in the $\mathrm{pH}$ range 3.5-9.5 (Pharmacia LKB, Piscataway, N.J.). The samples were subjected to electrophoresis for $90 \mathrm{~min}$ at $8 \mathrm{~W} \cdot \mathrm{cm}^{-2}$ at $10 \mathrm{C}$. The gels were then washed for $30 \mathrm{~min}$ in phosphate-buffered saline (PBS) [i.e., phosphate buffer solution containing. $10 \mathrm{mM}$ sodium phosphate buffer ( $\mathrm{pH}$ 6.0) and 150 $\mathrm{mM}$ sodium chloride] to remove the ampholines and ensure a uniform $\mathrm{pH}$ throughout the gel. Isoenzymes were made visible by development in $0.6 \mathrm{mg}$ 4-chloro-1-naphthol/ml in $1 \times \mathrm{PBS}$ and $0.018 \%$ hydrogen peroxide. After $\approx 15$ rein, blue bands indicated the location of the POD isoenzymes. The gels were washed briefly with $1 \times$ PBS and photographed.

Histochemical localization of POD activity. The localization of POD within the berry was achieved by an adaptation of the tissue blot method of Spruce et al. (1987). Freshly harvested berries of developmental stages 2-8 were sectioned along the calyx-stem axis. The exposed surface was pressed gently for 1 min onto water-moistened nitrocellulose filter paper that then was incubated for $1 \mathrm{~min}$ in a solution of $0.6 \mathrm{mg}$ 4-chloro-1naphthol/ml in $1 \times$ PBS. Hydrogen peroxide was subsequently added to achieve a final concentration of $0.018 \%$ for the development of peroxidase activity. A blue pigment on the filter paper indicated the location of POD activity in the berry.

The localization of POD activity was also performed with nitrocellulose filters that were presoaked in $0.2 \mathrm{M}$ calcium chloride before being placed in contact with the fruit.

\section{Results and Discussion}

$P O D$ assay. Enzyme activity, plotted as increase in absorbance at $470 \mathrm{~nm} \cdot \mathrm{min}^{-1} \cdot \mathrm{g}^{-1}$ of tissue peaked at ripeness stage 5 (Fig la). Calcium was effective in extracting POD, but very little activity was found without salt. The lowest POD activity was at stages 2 and 3, but a large increase in Ca-extracted POD was detected at stage 4 . The trend in activity was similar for both extracts but with a proportionally greater decline in stages 7 and 8 for the extract without $\mathrm{Ca}$.

A preliminary study showed that the addition of $\mathrm{Ca}$ to the salt-free extract did not enhance POD activity (data not shown). Therefore, it appears that $\mathrm{Ca}$ is desorbing the enzyme rather than activating it.

When the POD assay data were expressed per berry (Fig. lb), the same trend was observed as when expressed on a weight basis, except that activity of Ca-extracted enzyme appears to be maintained until stage 8 . POD activity per berry for the non-Ca extract was similar to the corresponding data based on weight (Fig. la), and accounted for only a small fraction of the total POD activity.

Isoelectric focusing. Insufficient enzyme was extracted by the $\mathrm{Ca}$-free medium to obtain visible activity in the gels. The electrophoretic pattern obtained with calcium chloride extraction showed that a single POD species observed during stages 2 and 3 persisted to maturity (Fig. 2). The intensity of this band increased during development and was the dominant band throughout. At stage 5, an isoenzyme appeared at the origin; its intensity increased only slightly but did not diminish during
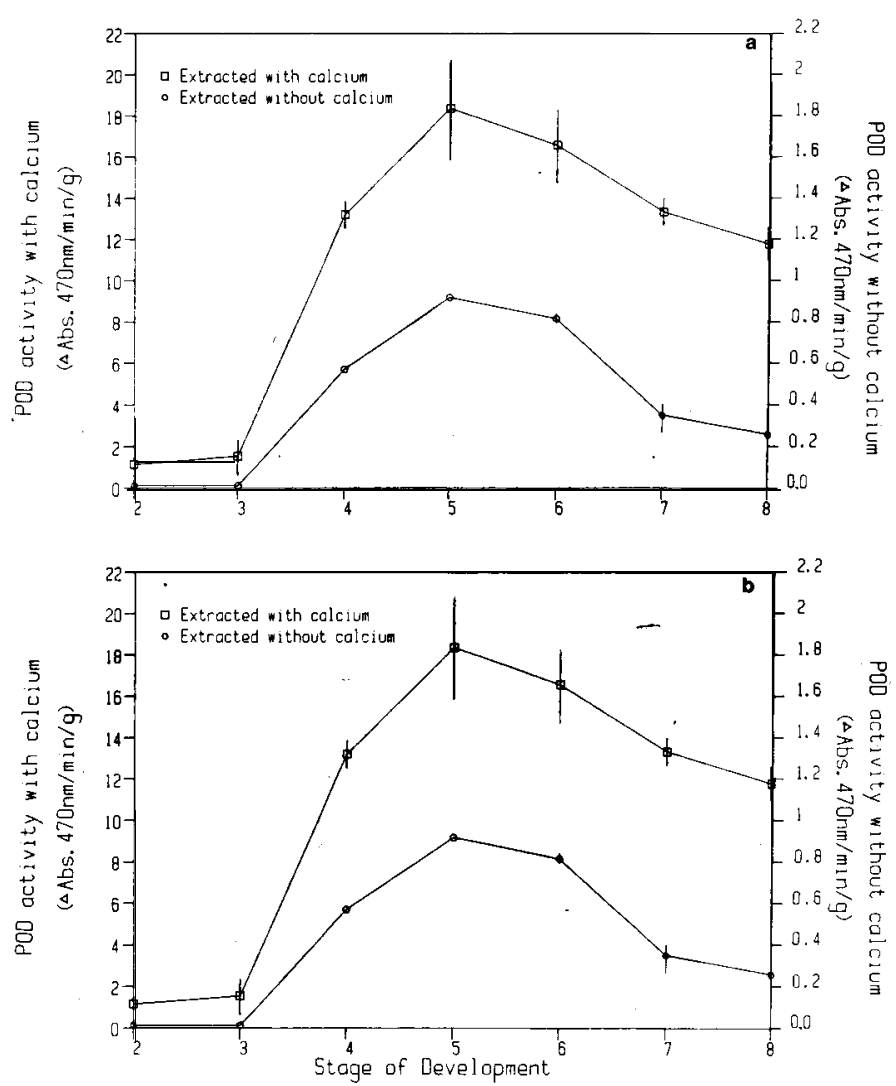

Fig. 1. POD activity extracted with and without the addition of 0.2 $\mathrm{M} \mathrm{Ca}$ to the extraction medium for blueberries in developmental stages 2-8 (see Materials and Methods). Enzyme activity was measured by the increase in absorbance at $470 \mathrm{~nm}$ in the presence of guaiacol and $\mathrm{H}_{2} \mathrm{O}_{2}$. Data are expressed on (a) a fresh-weight and (b) a per berry basis. Bars indicate standard deviation of duplicate determinations.

the study. At stages 7 and 8, a prominent band of activity close to the cathode was present, as well as some minor bands.

The number and intensity of POD isoenzymes increased during blueberry fruit development, particularly between stages 5 and 8 (Fig. 2). These results contradict the findings of Frenkel (1972), who reported a weakening in isoenzyme bands during ripening.

Histochemical localization of POD activity. The location of peroxidase activity at various stages of development is shown in Fig. 3. The patterns obtained from berries blotted to filters moistened with water reflected soluble POD activity. Berries blotted onto nitrocellulose filters treated with $0.2 \mathrm{M}$ calcium chloride revealed the location of both soluble and previously ionically bound enzyme.

Soluble enzyme activity was low and located primarily in the periphery and the center of the berry at stage 2 (Fig. 3a). During ripening, POD activity spread into the interior of the berry, and the intensity of the stain appeared greatest at stage 5. The locular region of the berry appeared devoid of activity until stage 7, when it was maximal; thereafter, the stain intensity declined.

As expected, extraction with salt increased the visible POD activity at all stages (Fig. 3b). Activity was observed during early development throughout the berry, particularly in the periphery and center. As the berries became more mature and softer, there was some loss of juice, which diffused the pattern of activity. Total activity was more intense at the final stage of ripening than at any other time. 


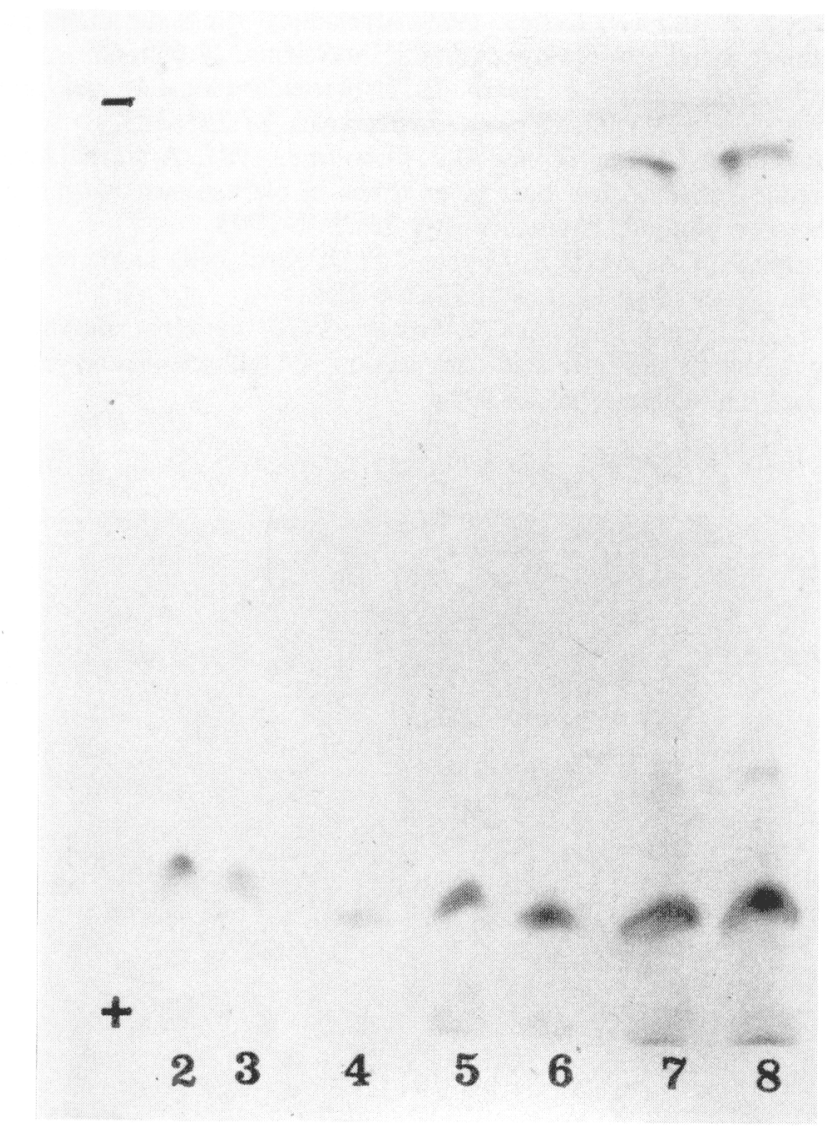

Fig: 2. POD isoenzymes obtained from blueberries at developmental stages 2-8 by isoelectric focusing on polyacrylamide gels using ampholytes in the $\mathrm{pH}$ range $3.5-9.5$.

The histochemical data were reproducible and confirmed the enzyme assay findings expressed on a per berry basis (Fig. lb), i.e., most POD in blueberries was in the bound form and activity highest in mature fruit. Initially, activity was most marked in areas of the epidermis, hypodermic, and center. Peroxidase may break down chlorophyll in peripheral cells and be active at the center of the berry in xylem Signification in the vascular bundles (Yarborough and Morrow, 1947). Free POD seems to be absent from what could be the locule of the berry in stages 1-3. The more generalized distribution of activity as maturity was appreached may indicate a role for POD in mesocarp and endocarp stone cell.. formation, xylem differentiation, and seed signification in the locule (Yarborough and Morrow, 1947). Peroxidase location could correspond to areas of lignin synthesis. Ranadive and Haard (1972) found that POD activity was prevalent in the parenchyma cells surrounding "grit cells" of pears and that most of the enzyme was in a bound form. They proposed that mineral nutrition limits POD localization and subsequent lignin deposition in pears. Calcium is a known activator of POD activity (Greppin, 1986). The limited uptake of Ca by highbush blueberry bushes in acid soils may also limit POD in blueberries.

In summary, POD appears to be mostly in a bound form. Its maximum activity, when expressed on a fresh-weight basis, coincides with berry softening. This coincidence indicates a possible function in cell wall modification. However, localization of peroxidase in the fruit also suggests a role in tissue signification. Electrophoretic data confirm the increase in activity during stage 5, but isozymes and more intense bands were present in extracts from stage 7 and 8 . Residual POD in harvested ma-
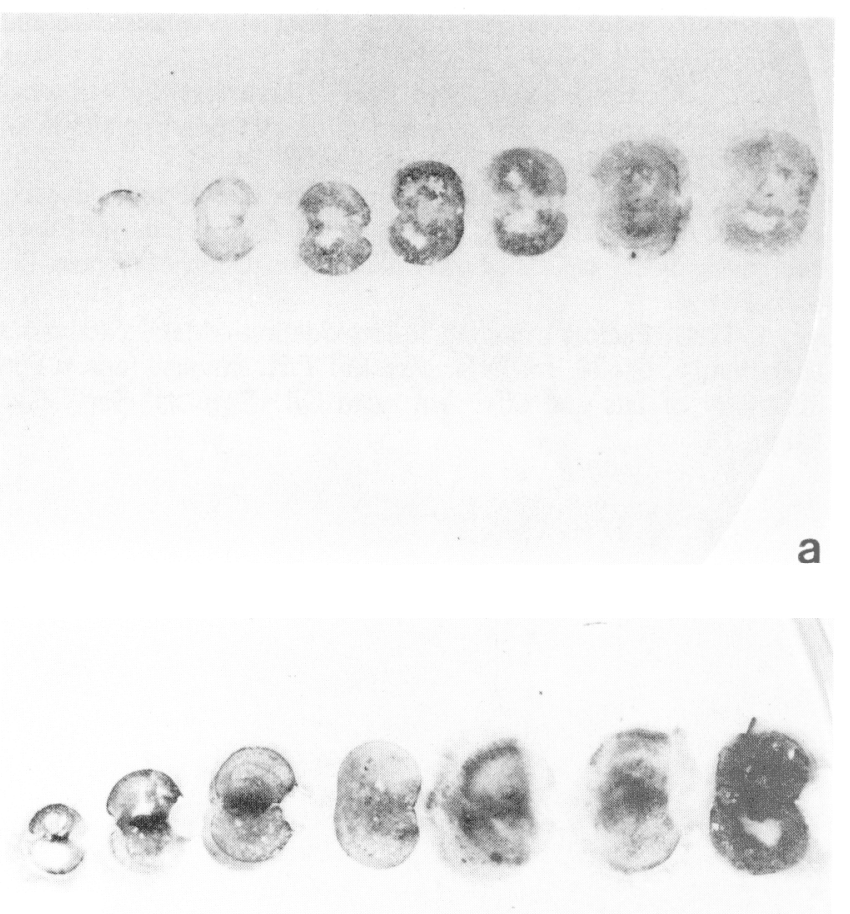

Fig. 3. Histochemical localization of blueberry POD on nitrocellulose paper (a) in the absence and (b) the presence of $\mathrm{Ca}$. Stages of development are 2-8 (left to right).

ture fruit may be important in natural and off-flavor formation due to interaction with unsaturated lipid components (Wang et al., 1990).

\section{Literature Cited}

Ballinger, W.E. and L.J. Kushman. 1970. Relationship of stage of ripeness to composition and keeping quality of highbush blueberries. J. Amer. Soc. Hort. Sci. 95:239-242.

Catesson, A. M., A. Imberty, R. Goldberg, and Y. Czaninski. 1986. Nature, location and specificity of peroxidases involved in signification processes, p. 189-198. In: H. Greppin, C. Penel, and T. Gasper (eds.). Molecular and physiological aspects of plant peroxidase. Univ. of Geneva Press, Switzerland.

Eck, P. 1988. The cultivated blueberry industry, p. 3-9. Blueberry science. Rutgers Univ. Press, New Brunswick, N.J.

Frenkel, C. 1972. Involvement of peroxidase and indole-acetic acid oxidase isoenzymes from pear, tomato, and blueberry fruit in ripening. Plant Physiol. 49:757-763.

Goldberg, R., A. Imberty, M. Liberman, and R. Prat. 1986. Relationships between peroxidase activities and cell wall plasticity, $\mathrm{p}$. 209-220. In: H. Greppin, C. Penel, and T. Gasper (eds.). Molecular and physiological aspects of plant peroxidase. Univ. of Geneva Press, Switzerland.

Grambow, H.J. 1986. Pathway and mechanism of the peroxidase-catalyzed degradation of indole-3-acetic acid, p. 31-41. In: H. Greppin, C. Penel, and T. Gasper (eds.). Molecular and physiological aspects of plant peroxidase. Univ. of Geneva Press, Switzerland.

Greppin, H. 1986. Peroxidase as a tool in studying the flowering process, p. 333-339. In: H. Greppin, C. Penel, and T. Gasper (eds.). Molecular and physiological aspects of plant peroxidase. Univ. of Geneva Press, Switzerland. 
Grommeck, R. and P. Markakis. 1964. Effect of peroxidase on anthocyanin pigments. J. Food Sci. 29:53-57

Lagrimini, L.M. and S. Rothestein. 1987. Tissue specificity of tobacco peroxidase isoenzymes and their induction by wounding and tobacco mosaic virus infection. Plant Physiol. 84:438-442.

Lamport, D.T.A. 1986. Roles for peroxidase in cell wall genesis, p. 199-208. In: H. Greppin, C. Penel, and T. Gasper (eds.). Molecular and physiological aspects of plant peroxidase. Univ. of Geneva Press, Switzerland.

Love, J. 1985. Factors affecting lipid oxidation -Metal catalysts and chelation, p. 61-78. In: D.B. Min and T.H. Smouse (eds.). Flavor chemistry of fats and oils. American Oil Chemists' Soc., Champaign, 111
Miller, A.R. and T.J. Kelley. 1989. Mechanical stress stimulates peroxidase activity in cucumber fruit. HortScience 24:650-652.

Ranadive, A.S. and N.F. Haard. 1972. Peroxidase location and lignin formation in developing pears. J. Food Sci. 27:381-383.

Spruce, J., A.M. Mayer, and D.J. Osboume. 1987. A simple histochemical method for locating enzymes in plant tissue using nitrocellulose blotting. Photochemistry 26:2901-2903.

Yarborough, J.A. and E.B. Morrow. 1947. Stone cells in Vaccinium. Proc. Amer. Soc. Hort. Sci. 50:224-228.

Wang, L. L., A.C. Peng, and A. Proctor. 1990. Varietal difference in lipid content and fatty acid composition of highbush blueberries. J. Amer. Oil Chem. Sot. 67:499. 